Hartmut Bomhoff

Ernst Ludwig Ehrlich - prägende Jahre 


\section{Europäisch-jüdische Studien Beiträge}

Herausgegeben vom Moses Mendelssohn Zentrum für europäisch-jüdische Studien, Potsdam, in Kooperation mit dem Zentrum Jüdische Studien Berlin-Brandenburg

Redaktion: Werner Treß

\section{Band 25}




\title{
Hartmut Bomhoff
}

\section{Ernst Ludwig Ehrlich - prägende Jahre}

Eine Biographie

\author{
DE GRUYTER \\ OLDENBOURG
}


Das Ernst Ludwig Ehrlich Studienwerk dankt der Leo Baeck Foundation für die Unterstützung des vorliegenden Bandes.

ISBN 978-3-11-041406-6

e-ISBN (PDF) 978-3-11-041421-9

e-ISBN (EPUB) 978-3-11-041429-5

\section{Library of Congress Cataloging-in-Publication Data}

A CIP catalog record for this book has been applied for at the Library of Congress.

\section{Bibliografische Information der Deutschen Nationalbibliothek}

Die Deutsche Nationalbibliothek verzeichnet diese Publikation in der Deutschen Nationalbibliografie; detaillierte bibliografische Daten sind im Internet über http://dnb.dnb.de abrufbar.

(C) 2015 Walter de Gruyter GmbH, Berlin/München/Boston

Satz: Dr. Rainer Ostermann, München

Personen- und Sachregister: Pierke Bosschieter, Stitswerd (Niederlande)

Druck und Bindung: $\mathrm{CPI}$ books $\mathrm{GmbH}$, Leck

@ Gedruckt auf säurefreiem Papier

Printed in Germany

www.degruyter.com 


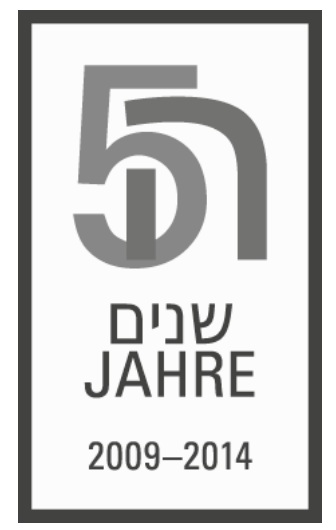

Fünf Jahre Ernst Ludwig Ehrlich Studienwerk 
